\title{
A New Coal-Permeability Model: Internal Swelling Stress and Fracture-Matrix Interaction
}

\author{
Hui-Hai Liu · Jonny Rutqvist
}

Received: 30 October 2008 / Accepted: 22 June 2009 / Published online: 17 July 2009

(C) The Author(s) 2009. This article is published with open access at Springerlink.com

\begin{abstract}
We have developed a new coal-permeability model for uniaxial strain and constant confining-stress conditions. The model is unique in that it explicitly considers fracture-matrix interaction during coal-deformation processes and is based on a newly proposed internal swelling stress concept. This concept is used to account for the impact of matrix swelling (or shrinkage) on fracture-aperture changes resulting from partial separation of matrix blocks by fractures that do not completely cut through the whole matrix. The proposed permeability model is evaluated using data from three Valencia Canyon coalbed wells in the San Juan Basin, where increased permeability has been observed during $\mathrm{CH}_{4}$ gas production, as well as using published data from laboratory tests. Model results are generally in good agreement with observed permeability changes. The importance of fracture-matrix interaction in determining coal permeability, demonstrated in this study using relatively simple stress conditions, underscores the need for a dual-continuum (fracture and matrix) mechanical approach to rigorously capture coal-deformation processes under complex stress conditions, as well as the coupled flow and transport processes in coal seams.
\end{abstract}

Keywords $\mathrm{CO}_{2}$ geological sequestration $\cdot$ Coal permeability $\cdot$ Enhanced coalbed methane recovery $\cdot$ Rock mechanics

\section{Introduction}

Anthropogenic emissions of $\mathrm{CO}_{2}$ into the atmosphere are recognized to have a significant effect on global warming, one of the most important problems facing society (e.g., Hansen 2004). Geological sequestration of $\mathrm{CO}_{2}$ is widely regarded as an essential component of a portfolio of approaches needed to reduce such emissions (Pacala and Socolow 2004). Because of the high internal surface area of coal, a comparatively large volume of $\mathrm{CO}_{2}$ can be stored as adsorbed gas in coal seams (Stevens etal. 2001; Cui etal. 2007). At the same time, the

H.-H. Liu $(\varangle)$ · J. Rutqvist

Earth Sciences Division, Lawrence Berkeley National Laboratory, Berkeley, CA 94720, USA

e-mail: hhliu@lbl.gov 
sequestration into coals displaces methane $\left(\mathrm{CH}_{4}\right)$ from coal and thus gives rise to enhanced production of coalbed methane. With this in mind, $\mathrm{CO}_{2}$ sequestration into deep, unminable coal seams is an attractive option with economic incentives. Recently, an excellent review of key issues related to this sequestration option (including potential storage capacity, the storage integrity of the geologic host, and the chemical and physical processes initiated by the deep underground injection of $\mathrm{CO}_{2}$ ) was presented by White et al. (2005).

One key parameter for $\mathrm{CO}_{2}$ sequestration in coal seams is coal permeability, because high coal permeability is required for sufficient and practical injectivity of $\mathrm{CO}_{2}$ into coal seams and for efficient recovery of $\mathrm{CH}_{4}$ (Cui et al. 2007). Results from field and laboratory experiments indicate that coal permeability can change significantly as controlled by at least two distinct mechanisms (Harpalani and Zhao 1989; Palmer and Mansoori 1998; Mavor and Vaughn 1997; Robertson 2005; White et al. 2005; Lin et al. 2008): (1) gas pressure increase, which tends to mechanically open coal cleats (fractures) and thus enhance coal permeability; and (2) adsoption of $\mathrm{CO}_{2}$ into coals, which induces swelling in the coal matrix (volumetric strain) and thus reduces coal permeability by narrowing and even closing fracture (cleat) apertures. Note that in this article, we will use either "fractures" or "cleats" to refer to coal cleats when discussing coal-permeability changes. We also like to indicate that the focus of this study is on relationship between coal permeability and these two mechanisms, rather than microscopic processes causing coal swelling. A discussion of the latter may be found in White etal. (2005).

A number of proposed coal-permeability models attempt to account for the mechanisms mentioned above. Sawyer et al. (1990) proposed a model assuming that fracture porosity (to which permeability can be directly related) is a linear function of changes in gas pressure and concentration. The proportionality constant is estimated by matching model results with measured permeability data. A recent discussion of this model was provided by Pekot and Reeves (2003). Seidle and Huitt (1995) developed a permeability model by considering the effects of coal-matrix swelling/shrinkage only, ignoring the impact of coal compressibility. Therefore, their model is limited to specific conditions in which sorption-induced strain (matrix swelling or shrinkage) dwarfs pressure-induced, elastic changes in cleat permeability (Robertson 2005). Palmer and Mansoori (1998) published a permeability model incorporating the combined effect of coal's elastic properties and gas sorption on the matrix strain. It includes a permeability loss term due to an increase in effective stress, and a permeability gain term resulting from matrix shrinkage as gas desorbs from the coal. Shi and Durucan (2003) proposed another coal permeability model by analyzing possible changes in effective horizontal stress under uniaxial strain conditions and relating the stress changes to fracture-permeability changes. Most recently, Robertson and Christiansen (2006) developed a permeability model for coal and other fractured, sorptive-elastic media. Contrary to previous models developed for field conditions, their model mainly deals with variable stress conditions commonly used during measurement of permeability in the laboratory.

While a certain degree of success has been achieved using the currently existing permeability models to explain and match experimental data, two important issues have not been fully addressed in these models. First, in all of these models, the interaction between fractures and coal matrix during coal deformation is not considered. Because coal matrix and fractures (cleats) have dramatically different mechanical properties, this interaction can have a significant effect on permeability changes under certain conditions, as will be demonstrated in this study. Although considerable effort has also been made with respect to modeling mechanical deformation processes and their coupling with flow processes in dual-continuum systems (fractured rock) (e.g., Wilson and Aifantis 1982; Bai et al. 1993; Berryman and Wang 1995), these studies have focused on developing governing equations for coupled liquid flow 
and mechanical processes, rather than determining relationships between permeability and other related properties. Second, the previously discussed permeability models also generally assume that a change in the length of a matrix block (resulting from swelling or shrinkage) causes an equal but opposite change in the fracture aperture. However, this is not consistent with some experimental observations indicating that only a fraction (rather than all) of sorption-induced strain (swelling or shrinkage) contributes to fracture-aperture change under certain stress conditions. For example, Robertson (2005) demonstrated that the most commonly used models (Palmer and Mansoori 1998; Shi and Durucan 2003) significantly overestimate the effects of matrix swelling on permeability changes observed from laboratory experiments performed under constant overburden (confining-stress) conditions.

The major objective of this study is to develop a new permeability model that explicitly considers fracture-matrix interaction during the coal-deformation process and also takes into account the partial contributions of matrix swelling/shrinkage to fracture-aperture changes under the constant confining-stress conditions commonly applied in laboratory experiments. The consistency of our model with both field and laboratory observations will also be demonstrated.

\section{The Concept of Internal Swelling Stress}

In this section, we first discuss how coal permeability is related to effective stress and then introduce our new concept of internal swelling stress. This concept is used to handle the partial contribution of matrix swelling/shrinkage to fracture-aperture changes.

\subsection{Fracture Permeability}

Coal seams are characterized by a dual-continuum system-namely, porous coal matrix and cleats (fractures). Permeability values for the coal matrix are typically eight orders of magnitude smaller than fracture permeability values (Robertson 2005). Therefore, most researchers generally ignore coal-matrix permeability and attribute coal permeability directly to fracture permeability. However, after reviewing relevant previous studies, Wei et al. (2007) concluded that multiphase flow processes within a coal matrix may have considerable effects on coalbed methane recovery processes, while these effects are largely ignored in current modeling practice. As a result, it may also be necessary to study the matrix permeability changes under different stress conditions. In this article, however, we focus on fracture permeability only.

Fracture permeability may be related to fracture aperture through the cubic law (Jaeger et al. 2007), while fracture aperture is generally a strong function of normal stress. Because of the similarity between coal-seam permeability-stress relationships and those for fractured rock, research results from the field of rock mechanics (focused on understanding fracture-matrix interactions and their effects on fracture permeability) can be utilized for this study. Recently, Liu et al. (2009) developed a new theoretical relationship between stress and elastic strain for porous and fractured rock, based on the reasoning that as a result of the heterogeneous nature of rock materials, different varieties of Hooke's law should be applied for different regions of the rock having significantly different stress-strain behaviors. They applied this idea by dividing a rock body (or a fracture) conceptually into two distinct parts, and further argued that the natural strain (volume change divided by rock volume at the current stress state), rather than the engineering strain (volume change divided by the unstressed rock volume), should be used in Hooke's law for accurate modeling of the 
elastic deformation of the part subject to a relatively large degree of relative deformation. Their theoretical results are supported by different types of experimental data for fractured rock. Their derived relationship between fracture aperture $(b)$ and the normal stress is given as follows:

$$
b=b_{\mathrm{r}}+b_{\mathrm{f}} \exp \left(-C_{\mathrm{f}} \sigma_{\mathrm{f}}\right)
$$

where $b_{\mathrm{r}}$ is the residual fracture aperture, $b_{\mathrm{f}}$ is the stress-sensitive portion of the fracture aperture, $C_{\mathrm{f}}$ is the fracture compressibility, and $\sigma_{\mathrm{f}}$ is the effective stress acting on the fracture. The above equation is similar to an empirical relationship proposed by Rutqvist et al. (2002). Based on the cubic law and the above equation, the permeability ratio at two different stress levels can be given by

$$
\frac{k}{k_{0}}=\left[\frac{\eta+e^{-C_{\mathrm{f}} \sigma}}{\eta+e^{-C_{\mathrm{f}} \sigma_{0}}}\right]^{3}
$$

where $k$ and $k_{0}$ are the coal permeabilities for effective stresses $\sigma_{\mathrm{f}}$ and $\sigma_{0}$, respectively, and parameter $\eta=b_{\mathrm{r}} / b_{\mathrm{f}}$. For a zero (or negligibly small) residual fracture aperture, the above equation is reduced to:

$$
\frac{k}{k_{0}}=\exp \left[-3 C_{\mathrm{f}}\left(\sigma-\sigma_{0}\right)\right]
$$

The existence of the residual fracture aperture for fractured rock has been well documented in the rock-mechanics literature (e.g., Rutqvist et al. 2002; Liu et al. 2009). However, the existence of such an aperture is not totally clear yet for coal cleats. For example, experimental measurements have indicated that coal permeability decreases exponentially with increasing effective stress (Somerton etal. 1975; Durucan and Edwards 1986), which seems to be consistent with Eq.3, corresponding to zero residual apertures. Permeability relationships essentially identical to Eq. 3 were previously presented by several other researchers (McKee etal. 1987; Seidel et al. 1992; Shi et al. 2004). In this study, we focus on Eq. 3, whereas the more general Eq. 2 may be needed if the residual fracture aperture is important in coal seams under certain conditions.

\subsection{Internal Swelling Stress}

For the purpose of estimating coal-permeability values, cleats (fractures) in coal seams are generally conceptualized with a matchstick geometry consisting of two sets of vertical fractures (Seidel et al. 1992; Harpalani and Chen 1995), as shown in Fig. 1. For such a fracture geometry, coal matrix blocks are completely separated by fractures. Based on Biot's theory, the effective stress is defined as (Jaeger et al. 2007)

$$
\sigma=\sigma_{\mathrm{t}}-\alpha P
$$

where $\sigma_{\mathrm{t}}$ is the total stress, $P$ is the fluid pressure, and $\alpha$ is Biot's coefficient. Note that compressive stress is here considered positive. Based on previous studies (e.g., Gray 1987; Shi etal. 2004), the Biot's coefficient is considered to be one in this study, although our theoretical development allows for arbitrary coefficient values.

For the fracture geometry shown in Fig. 1, matrix swelling will not affect coal permeability under the constant confining (total) stress conditions commonly used in laboratory measurements, because the effective stress defined in Eq. 4 has nothing to do with the matrix swelling, 


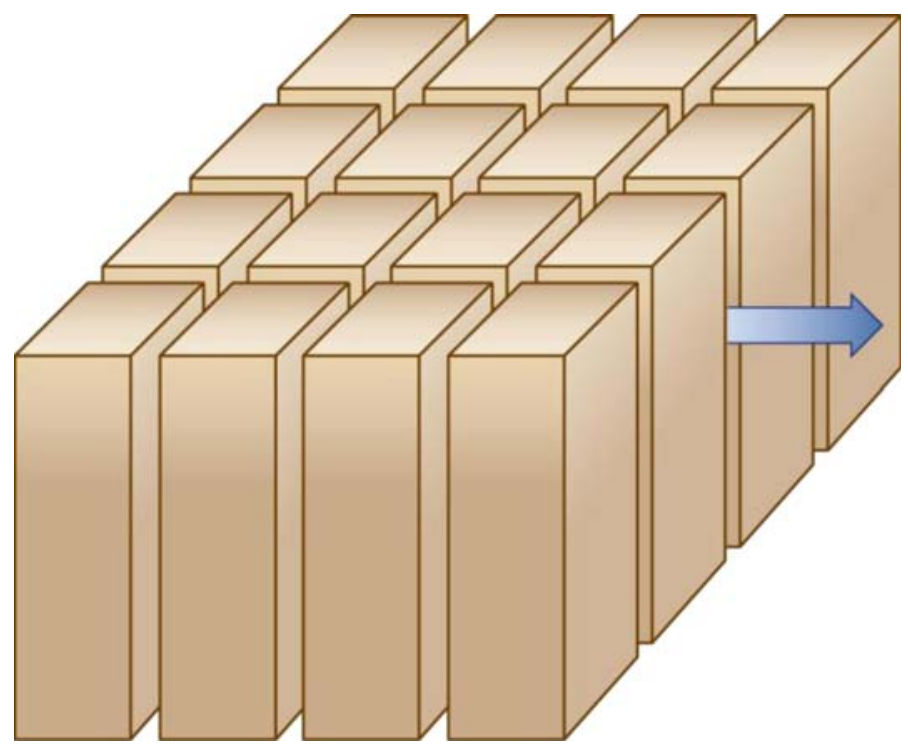

Fig. 1 Matchstick fracture (cleat) geometry showing flow through vertical fractures only

as a result of the complete separation between matrix blocks caused by through-going fractures. In this case, for a given pressure $P$, the swelling will result in increasing fracture spacing, rather than changes in fracture aperture. However, this is not consistent with laboratory measurements that show significant effects of matrix swelling on coal permeability under constant confining-stress conditions. In order to explain these effects, a number of researchers simply assumed a zero lateral strain condition in the horizontal plane, such that matrix swelling can affect coal permeability (e.g., Harpalani and Chen 1995; Robertson and Christiansen 2006). This is inconsistent with the fracture geometry (under constant stress conditions) shown in Fig. 1 and the concept of Biot's effective stress. This treatment also overestimates the effects of matrix swelling on permeability changes observed in laboratory (Robertson 2005).

The above discrepancy results from the oversimplification of coal fracture systems in Fig. 1. In reality, coal matrix blocks are not completely separated from each other by fractures. Figure 2 shows a simplified horizontal cross section of a coal seam with two adjacent vertical fractures, separated by a coal-matrix "bridge" that connects matrix blocks on the different sides of fractures. During matrix swelling, fractures are compressed, because they are weak and soft structures within the coal seams, and therefore an additional force (corresponding to stress $\sigma_{\mathrm{I}}$ ) will be imposed on the fractures. At the same time, the matrix bridge would be subject to an additional force in the opposite direction to $\sigma_{\mathrm{I}}$. If these two forces are completely balanced, fractures will be subject to this additional stress $\sigma_{\mathrm{I}}$, while confining stress remains unchanged. Because this stress largely results from internal structures (or connectivity of matrix blocks) within coal seams and can be internally balanced under constant confining-stress conditions, we call it "internal swelling stress". In this case, the effective stress for fractures in coal seams should be given as

$$
\sigma=\sigma_{\mathrm{t}}-\alpha P+\sigma_{\mathrm{I}}
$$

Note that $\sigma_{\mathrm{I}}$ is positive for matrix swelling and negative for matrix shrinkage. Our new definition of effective stress is able to explain the effects of matrix swelling/shrinkage on 


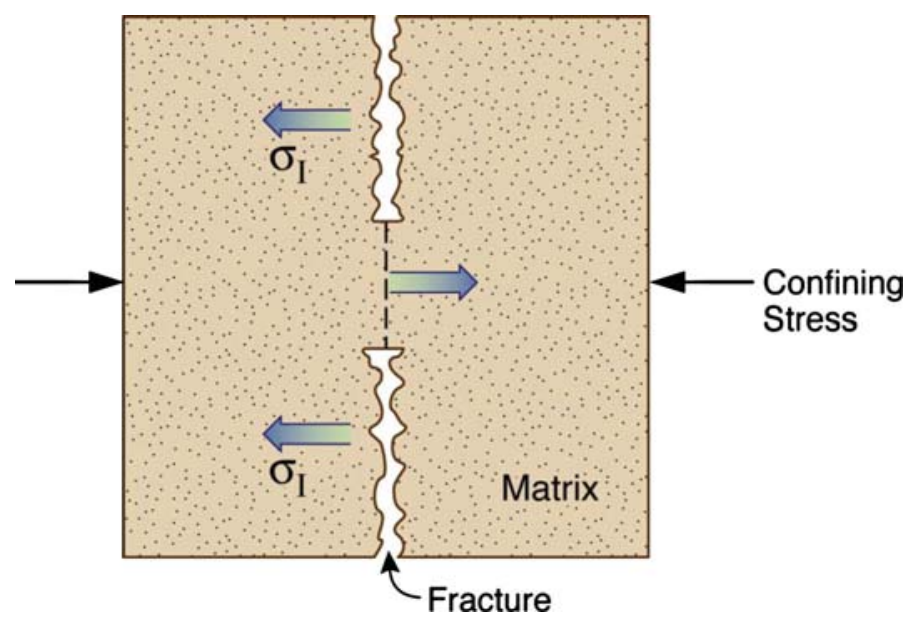

Fig. 2 A schematic description of internal swelling stress

coal permeability, because effective stress will change as a result of swelling/shrinkage, even when the confining stress and fluid pressure remain unchanged.

Our concept of internal swelling stress implies that coal-matrix strain resulting from swelling $\left(\varepsilon_{\mathrm{s}}\right)$ can be divided into two parts:

$$
\varepsilon_{\mathrm{s}}=\varepsilon_{\mathrm{SB}}+\varepsilon_{\mathrm{SI}}
$$

where $\varepsilon_{\mathrm{SI}}$ is the strain corresponding to the internal swelling stress, and $\varepsilon_{\mathrm{SB}}$ is the strain contributing to the bulk strain for a fractured coal seam. It is $\varepsilon_{\mathrm{SI}}$ (a portion of $\varepsilon_{\mathrm{S}}$ ) that results in coal permeability changes under constant confining-stress conditions. This is why the use of the total matrix strain $\left(\varepsilon_{\mathrm{s}}\right)$ overestimates permeability changes under those conditions. In general, $\varepsilon_{\mathrm{s}}$ can be directly measured in the laboratory. The relationship between $\varepsilon_{\mathrm{s}}$ and $\varepsilon_{\mathrm{sI}}$ may be a complex function of matrix block connectivity within coal seams and other relevant factors. As a first approximation, we assume the ratio between the two strains to be a constant at this point:

$$
\varepsilon_{\mathrm{SI}} \approx f \varepsilon_{\mathrm{s}}
$$

where $f$ is a constant between zero and one. This treatment will be evaluated against laboratory measurements below, while we acknowledge that more studies in the future may be needed to develop more rigorous relationships between $f$ and other properties. One potentially useful approach for this development may be homogenization that derives macroscopic constitutive relations from microscopic results (Moyne and Murad 2006a, b).

It is of interest to compare approach in this study to determining effective stress with previous studies associated with swelling (e.g., Rutqvist et al. 2001; Cui et al. 2007) and volume changes of rock matrix owing to temperature changes (e.g., Jaeger et al. 2007). In all these other studies, effective stress is defined using Eq. 4. Volume changes (swelling) are accounted for as (bulk) strains and their impacts on deformation processes are determined through Hooke's law and Eq. 4. In other words, these treatments do not consider the internal swelling stress proposed in this study. They are reasonable for single-continuum systems (such as clay soil or rock matrix), while the internal swelling stress becomes important for dual-continuum systems (such as fractured coal seams or rock). 


\section{Coal-Permeability Model}

In this section, we derive a new coal-permeability model based on the concept of internal swelling stress and considering fracture-matrix interaction. The model will be developed for uniaxial strain conditions and constant confining-stress conditions. The former is generally considered to be consistent with field stress conditions (e.g., Palmer and Mansoori 1998; Shi et al. 2004); the latter is commonly used in laboratory tests (e.g., Harpalani and Chen 1995; Robertson 2005). The fracture geometry shown in Fig. 1 is still used here for our model development, except that the internal connections between matrix blocks are accounted through the concept of internal swelling stress.

\subsection{Uniaxial Strain Condition}

Based on Hooke's law, a general relationship between stress and strain increments is given by (Jaeger et al. 2007)

$$
\Delta \varepsilon_{x}=\frac{1}{E}\left[\Delta \sigma_{x}-v\left(\Delta \sigma_{y}+\Delta \sigma_{z}\right)\right]
$$

where $E$ and $v$ are the Young's modulus and Poisson's ratio of the coal matrix. Subscripts $x, y$ and $z$ refer to two horizontal directions (normal to fracture plan of the two sets of vertical fractures) and vertical direction, respectively. Considering stress increments in the two horizontal directions ( $x$ and $y$ ) to be the same (isotropic assumption) and dropping the subscript for the $x$ direction, Eq. 8 can be rearranged as

$$
\Delta \varepsilon_{x}=\frac{1}{E}\left[\Delta \sigma(1-v)-v \Delta \sigma_{z}\right]
$$

This is a basic relationship used for deriving our coal-permeability model under uniaxial conditions.

In order to clearly demonstrate the role of fracture-matrix interaction, we divide the coal-deformation process into two steps (for mathematical derivation purposes). As shown in Fig. 3, first consider that there is no change in the effective stress at the fracture-matrix interface. The movement of the interface results from coal-matrix deformation owing to gas pressure change and matrix swelling. The strain change purely owing to pressure change can be obtained from Eq. 9 under the conditions $\Delta \sigma_{z}=-\Delta P$ (from Eq.5) and $\Delta \sigma=0$ (resulting from no change in effective stress at the fracture-matrix interface):

$$
\Delta \varepsilon_{x P}=\frac{\Delta L_{\mathrm{p}}}{L_{0}}=\frac{v \Delta P}{E}
$$

As discussed in Sect. 2, the matrix strain induced by matrix swelling can be divided into two parts: one contributes to the internal swelling stress and the other one is related to the bulk strain of coal seams under constant confining stress conditions. However, under the specific uniaxial strain condition ( $L_{0}$ remains unchanged in Fig. 3), both parts contribute to fracture changes in an identical manner. As a result, in this special case, it is unnecessary to treat the two parts differently, and the total strain is considered in our derivation. Recent studies (Harpalani and Chen 1995; Seidle and Huitt 1995; Robertson 2005) have shown that laboratory-measured matrix swelling (or shrinkage) can be directly correlated to the amount of adsorbed gas that is generally described by the Langmuir equation. Specifically, the swelling (or shrinkage)-induced matrix-strain change can be given by 


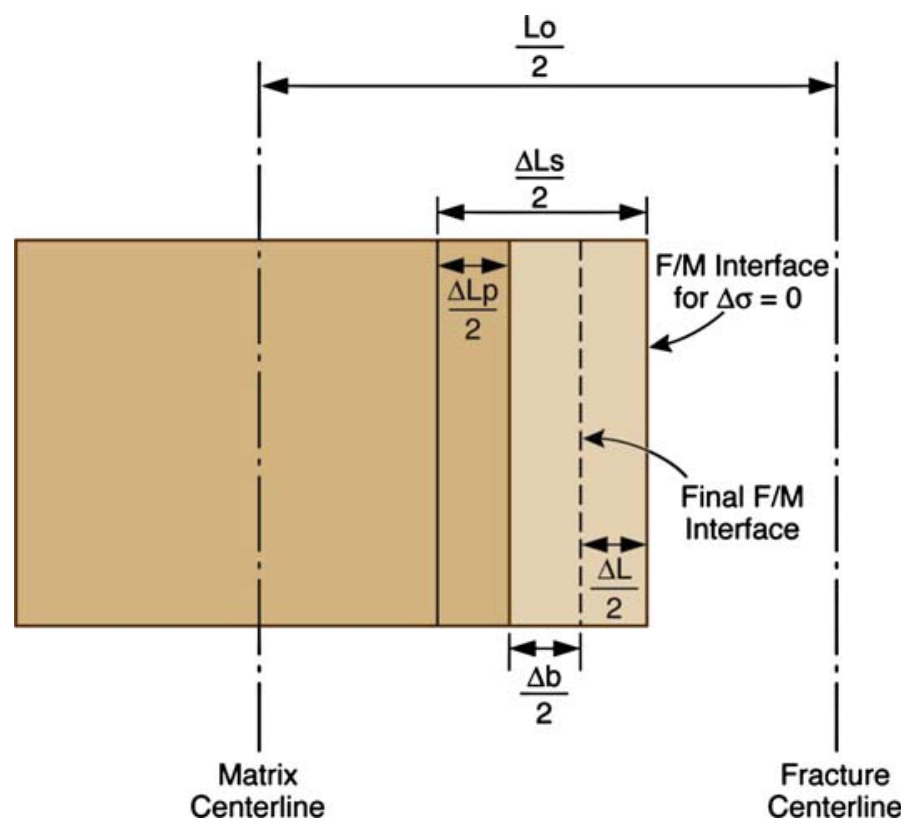

Fig. 3 Coal deformation under uniaxial conditions

$$
\Delta \varepsilon_{\mathrm{s}}=\frac{\Delta L_{\mathrm{s}}}{L_{0}}=S_{\max }\left(\frac{P}{P+P_{\mathrm{L}}}-\frac{P_{0}}{P_{0}+P_{\mathrm{L}}}\right)
$$

where the (linear) Langmuir strain $S_{\max }$ is a constant representing the strain at infinite gas pressure, and the Langmuir pressure $P_{\mathrm{L}}$ is another constant representing gas pressure at which the measured strain is equal to one-half $S_{\max }$. Both constants can be determined from laboratory measurements. The subscript " 0 " refers to initial conditions in this article. We also note that a number of researchers have derived theoretical relationships for chemo-mechanical coupling in swelling clays based on physical and chemical processes at microscopic scales (e.g., Loret et al. 2002). While these studies may be useful for understanding the swellinginduced matrix-strain change, we use Eq. 11 in this study because it is relatively simple and supported by experimental results.

At this point, the total fracture-matrix interface movement $\left(\Delta L_{\mathrm{s}}-\Delta L_{\mathrm{p}}\right)$ is achieved for unchanged effective stress at the fracture-matrix interface. Because of the resistance of the fracture, the actual interface location will be different from the one determined by $\Delta L_{\mathrm{s}}-\Delta L_{\mathrm{p}}$, as shown in Fig. 3. This difference will result in a change in effective stress for the fracture. In other words, the change in effective stress for fractures should be the same as that needed to push the interface location (without considering fracture resistance) back to where the final interface is located after considering fracture stiffness effects (Fig. 3). From Eq. 9 and considering $\Delta \sigma_{z}=0$ during this "push-back" step, the final change in effective stress for the fracture can be obtained as

$$
\Delta \sigma=\frac{E \Delta \varepsilon_{x}}{1-v}
$$

where

$$
\Delta \varepsilon_{x}=\frac{\Delta L}{L_{0}}=\frac{\Delta L_{\mathrm{s}}-\Delta L_{\mathrm{p}}-\Delta b}{L_{0}}=\Delta \varepsilon_{\mathrm{s}}-\Delta \varepsilon_{\mathrm{p}}-\Delta \varepsilon_{\mathrm{f}}
$$


Combining (10)-(13) yields

$$
\Delta \sigma=-\frac{v}{1-v} \Delta P+\frac{E\left(\Delta \varepsilon_{\mathrm{s}}-\Delta \varepsilon_{\mathrm{f}}\right)}{1-v}
$$

where $\Delta \varepsilon_{\mathrm{f}}=\frac{\Delta b}{L_{0}}$ is positive when fracture aperture is reduced. Based on Eq. 1 and assuming $b_{\mathrm{r}}=0$, one can obtain

$$
\Delta \varepsilon_{\mathrm{f}}=\frac{1}{2} \phi_{0}\left(1-e^{-C_{\mathrm{f}} \Delta \sigma}\right)
$$

where $\phi_{0}=\frac{b_{0}}{L_{0}}$ is initial fracture porosity.

Equations 3, 11, 14, and 15 together comprise our new model for coal permeability. When $\Delta \varepsilon_{\mathrm{f}}=0$, our model is reduced to the commonly used model proposed by Shi and Durucan (2003), who did not consider fracture-matrix interaction during the coal-deformation process. As will be shown later, this interaction can have a considerable effect on permeability predictions. We also note that an iteration procedure is needed to determine $\Delta \sigma$ using Eqs. 14 and 15. The iteration can start with assuming $\Delta \sigma=0$ in Eq. 15, and then updating $\Delta \sigma$ and $\Delta \varepsilon_{\mathrm{f}}$ using Eqs. 14 and 15, respectively, until the change in calculated values of $\Delta \sigma$ (or permeability) in the two consequent iterations can be practically ignored. Our experience suggests that iteration converges very quickly with respect to reasonable mechanical property values for coal.

\subsection{Constant Confining-Stress Condition}

A constant confining-stress condition is often used in the laboratory for measuring coal permeability resulting from matrix swelling (or shrinkage). A permeability model for such a condition is needed for interpreting the corresponding laboratory measurements.

Changes in effective stress for fractures can be directly determined from the definition of the effective stress (Eq.5) as

$$
\Delta \sigma=-\Delta P+\Delta \sigma_{\mathrm{I}}
$$

Contrary to the case under uniaxial strain condition, only a portion of the swelling-induced strain, $\Delta \varepsilon_{\text {SI }}$ (Eq. 6), contributes to effective stress change. Since $\Delta \varepsilon_{\text {SI }}$, by definition, does not contribute to the bulk strain of coal seams, the effective stress change owing to $\Delta \varepsilon_{\mathrm{SI}}, \Delta \sigma_{\mathrm{I}}$, can be determined under a zero horizontal strain condition similar to the uniaxial strain condition. Based on the procedure to derive Eq. 12, one obtains

$$
\Delta \sigma_{\mathrm{I}}=\frac{E\left(\Delta \varepsilon_{\mathrm{sI}}-\Delta \varepsilon_{\mathrm{fI}}\right)}{1-v}
$$

where

$$
\Delta \varepsilon_{\mathrm{fI}}=\frac{1}{2} \phi_{0}\left(1-e^{-C_{\mathrm{f}} \Delta \sigma_{\mathrm{I}}}\right)
$$

The above equation is developed following the similar procedure to derive Eq. 15. Combining Eqs. 7, 16, and 17 yields

$$
\Delta \sigma=-\Delta P+\frac{E\left(f \Delta \varepsilon_{\mathrm{s}}-\Delta \varepsilon_{\mathrm{fI}}\right)}{1-v}
$$

Equations 3, 11, 18 and 19 comprise our permeability model for constant confining-stress conditions. As previously indicated, parameter $f$ in Eq. 19 might be a complex function of 


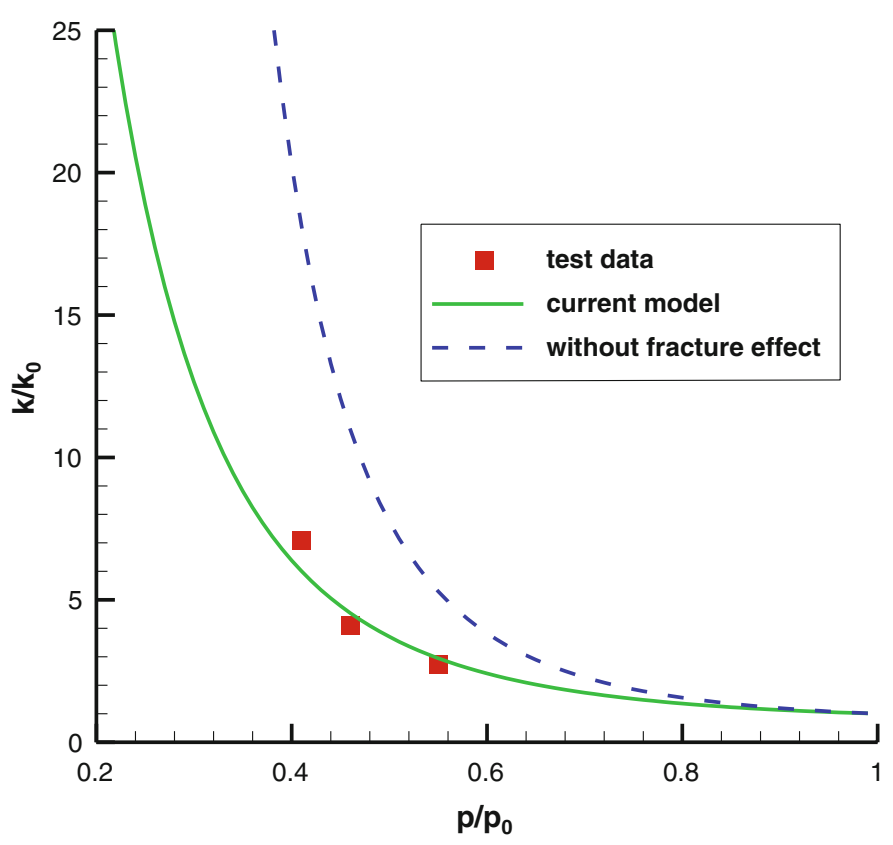

Fig. 4 Comparison between the model results and the observed San Juan basin permeability changes

matrix block connectivity within coal seams and other relevant factors. As a first degree of approximation, we treat it as a constant and determine its value from the relevant laboratory measurements.

\section{Model Evaluation and Discussions}

It is generally believed that uniaxial strain is a reasonable approximation of field-scale mechanical conditions for coal seams. Therefore, our permeability model developed for uniaxial strain conditions was evaluated using field data. Mavor and Vaughn (1997) reported on well tests conducted at three wells in the Valencia Canyon area of the San Juan Basin (where coal rank ranges from subbituminous to bituminous) and found that permeability, with decreasing gas pressure, increased between 2.7 and 7.1 times the initial permeability values (Fig.4). The initial gas pressures for the three wells are 5.35, 6.60, and 6.41 MPa, respectively. Because of the slight differences among these initial gas pressures, an averaged value is used for all the three wells in our model evaluation. The following mechanical properties and matrix swelling parameters are taken directly from Shi etal. (2004): $v=0.30$, $E=2,900 \mathrm{MPa}, P_{\mathrm{L}}=2.55 \mathrm{MPa}$, and $S_{\max }=0.0043$. The initial fracture porosity is $0.05 \%$ (Mavor and Vaughn 1997). These values are representative of the San Juan basin coalbed. Figure 4 shows that our model satisfactorily matches permeability changes from the three wells. The match is obtained by adjusting fracture compressibility $\left(C_{\mathrm{f}}\right)$; the calibrated value for $C_{\mathrm{f}}$ is $0.43 \mathrm{MPa}^{-1}$.

Similar matches shown in Fig. 4 have also been reported with the Shi-Durucan model (Shi et al. 2004) and Palmer-Mansoori model (Mavor and Vaughn 1997). However, different models generate different calibrated parameter values, because of the non-uniqueness 
Table 1 Properties of coal cores used in laboratory permeability experiments (Robertson 2005)

\begin{tabular}{lll}
\hline & Anderson & Gilson \\
\hline$\phi_{0}$ & $1.31 \%$ & $0.804 \%$ \\
$v$ & 0.35 & 0.35 \\
$E($ psi $)$ & 200,000 & 200,000 \\
$S_{\max }$ & 0.03527 & 0.01559 \\
$P_{\mathrm{L}}($ psia $)$ & 555.25 & 555.25 \\
\hline
\end{tabular}

of curve fitting. Our calibrated $C_{\mathrm{f}}$ value is about 1.5 times the value obtained by Shi et al. (2004). To the best of our knowledge, our permeability model is the first that considers the fracture-matrix interaction in the coal-deformation process. In general, fitted parameter values should be more reliable when related processes are more accurately captured in the corresponding model. In order to further evaluate the impact of fracture-matrix interaction on permeability change, Fig. 4 also shows permeability curve calculated without considering fracture-matrix interaction $\left(\Delta \varepsilon_{\mathrm{f}}=0\right.$ in Eq. 14). Both curves in Fig. 4 (with and without considering fracture-matrix interaction) are obtained using the same values for coal mechanical properties and matrix swelling parameters. The considerable differences between the two curves suggest that fracture-matrix interaction is important for permeability changes in coal seams, and that these changes would be overestimated without considering the interaction for the same relevant parameter values.

Constant confining-stress conditions are often used in the laboratory for measuring permeability changes. Our permeability model developed for such conditions (Sect. 3.2) is evaluated with laboratory data for two coal types [Anderson (subbituminous coal) and Gilson (bituminous coal)] reported by Robertson (2005). This data set is well documented and allows for independent determination of fracture compressibility $\left(C_{\mathrm{f}}\right)$ values. The $C_{\mathrm{f}}$ values are obtained by fitting Eq. 1 to the permeability data obtained with constant gas pressure (resulting in no changes in matrix swelling) and different confining stresses. These values are $2.26 \times 10^{-4}$ and $2.85 \times 10^{-4} \mathrm{psi}^{-1}$, respectively, for Anderson and Gilson coals. Values for other mechanical properties and swelling parameters are directly obtained from Robertson (2005), as shown in Table 1. (Note that to be consistent with original data set, we use a pressure unit (psi) here different from that used for model evaluation with field data.) The only parameter needing adjustment for matching the data (for pure $\mathrm{CO}_{2}$ gas) is $f$ (Eq. 19).

As shown in Figs. 5 and 6, fairly good matches are obtained between model results (with $f$ values much smaller than one) and permeability data, suggesting that our assumption of constant $f$ seems to be adequate, at least for the data set under consideration. At the same time, we acknowledge that more studies are needed to determine how $f$ is related to the relevant processes and parameters, as previously indicated. For comparison purposes, Figs. 5 and 6 also show permeability curves calculated without considering fracture-matrix interaction. Again, the considerable differences between permeability curves with, and without, considering fracture-matrix interactions support the importance of including this interaction in predicting permeability changes, although the differences (Figs. 5, 6) seem to be smaller than those for uniaxial strain conditions (Fig. 4). In Figs. 5 and 6, permeability curves calculated with $f=1$ are also presented. They significantly overestimate the effects of matrix swelling, which are consistent with the evaluations of Robertson (2005) for several commonly used permeability models. This supports the validity of the concept of internal swelling stress and the related argument that only a fraction of matrix strain owing to swelling contributes to the permeability change under constant confining-stress conditions. 


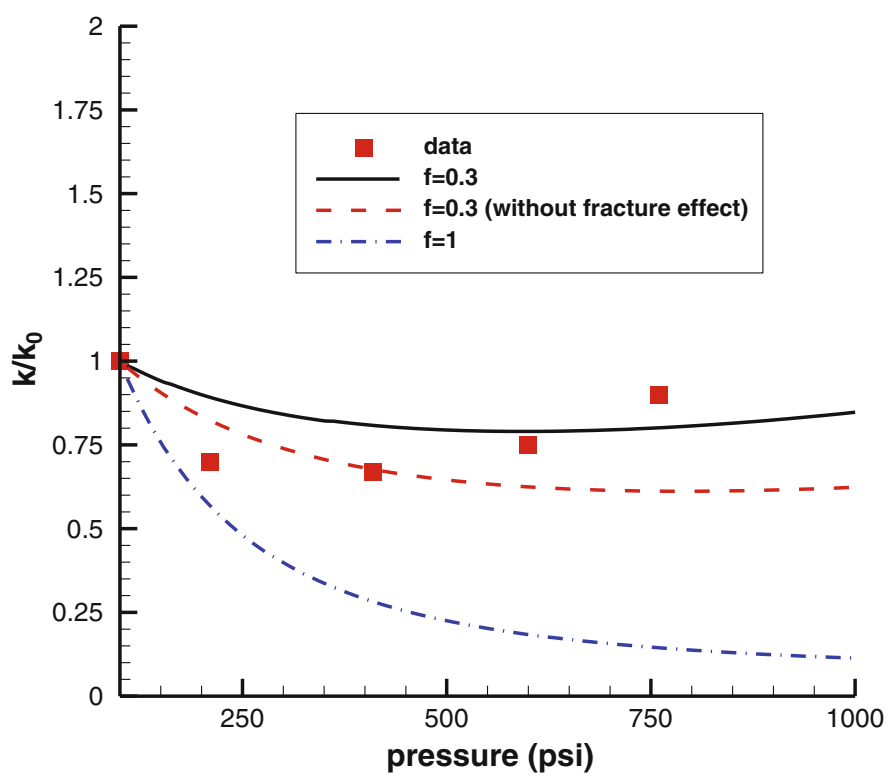

Fig. 5 Comparison between the model results and the observed coal (Anderson)-permeability changes measured in laboratory for pure $\mathrm{CO}_{2}$ gas (Robertson 2005)

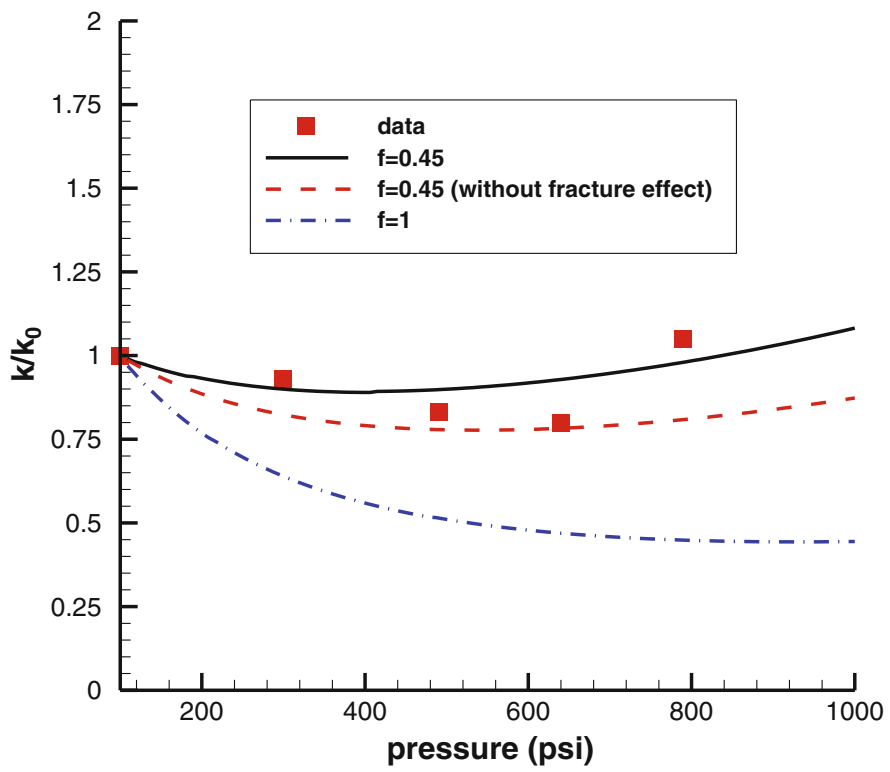

Fig. 6 Comparison between the model results and the observed coal (Gilson)-permeability changes measured in laboratory for pure $\mathrm{CO}_{2}$ gas (Robertson 2005) 


\section{Concluding Remarks}

One key parameter for $\mathrm{CO}_{2}$ sequestration in coal seams is coal permeability, because high coal permeability is required for sufficient and practical injectivity of $\mathrm{CO}_{2}$ into coal seams. In this article, we developed a new permeability model for both uniaxial strain and constant confining-stress conditions. Our model is unique, in that it explicitly considers fracture-matrix interaction during coal-deformation processes, and is based on a newly proposed internal swelling stress concept. In order to accurately predict coal permeability changes, effective stress needs to include this internal swelling stress as an additional term. Our permeability model for uniaxial strain conditions was evaluated with data from three Valencia Canyon coalbed wells in the San Juan Basin, where increased permeability has been observed during $\mathrm{CH}_{4}$ gas production. Model results were in good agreement with these field observations. The permeability model for constant confining-stress conditions was also evaluated using a laboratory data set. Again, model results were shown to be consistent with the data set, supporting our argument that only a fraction of matrix strain resulting from swelling (or shrinkage) contributes to fracture-aperture change under certain conditions.

Finally, we must emphasize that our model, similar to other existing permeability models, was developed for relatively simple mechanical conditions: uniaxial strain and constant confining stress. While uniaxial strain may be valid for a relatively large basin scale, mechanical conditions at local scale are expected to be much more complex in coal seams. In order to more accurately model $\mathrm{CO}_{2}$ sequestration processes in coal seams involving coupled liquid flow and mechanical deformation, a dual-continuum (fracture versus matrix) mechanical approach is required for more rigorously capturing the coal-deformation processes under complex stress conditions. It is our hope that this study can serve as a first step toward the development of such a dual-continuum framework for coupled hydraulic and mechanical processes in coal seams.

Acknowledgements We are indebted to Teamrat A. Ghezzehei at Lawrence Berkeley National Laboratory for his critical and careful review of a preliminary version of this manuscript. Helpful comments of two referees are also gratefully acknowledged. This study was supported by the U.S. Department of Energy (DOE) under DOE Contract No. DE-AC02-05CH11231.

Open Access This article is distributed under the terms of the Creative Commons Attribution Noncommercial License which permits any noncommercial use, distribution, and reproduction in any medium, provided the original author(s) and source are credited.

\section{References}

Bai, M., Elsworth, D., Roegiers, J.C.: Multiporosity/multipermeability approach to the simulation of naturally fractured reservoirs. Water Resour. Res. 29, 1621-1633 (1993)

Berryman, J.G., Wang, H.F.: The elastic coefficients of double-porosity models for fluid transport in jointed rock. J. Geophys. Res. 100(B12), 24611-24627 (1995)

Cui, X., Bustin, R.M., Chikatamarla, L.: Adsorption-induced coal swelling and stress: implications for methane production and acid gas sequestration into coal seams. J Geophys. Res. (2007). doi:10.1029/ 2004JB003482

Durucan, S., Edwards, J.S.: The effects of stress and fracturing on permeability of coal. Min. Sci. Technol. 3, 205-216 (1986)

Gray, I.: Reservoir engineering in coal seams: part 1-the physical process of gas storage and movement in coal seams. SPE Reserv. Eng., 2(1), 28-34 (1987)

Hansen, J.E.: Defusing the global warming time bomb. Sci. Am. 290, 68-77 (2004)

Harpalani, S., Chen, G.: Estimation of changes in fracture porosity of coal with gas emission. Fuel 74, 1491-1498 (1995) 
Harpalani, S., Zhao, X.: An investigation of the effect of gas desorption on gas permeability. In: Proceedings of the Coalbed Methane Symposium, University of Alabama, Tuscaloosa, Alabama, pp. 57-64 (1989)

Jaeger, J.C., Cook, N.G.W., Zimmerman, R.W.: Fundamentals of Rock Mechanics. Blackwell Publishing, Malden (2007)

Lin, W., Tang, G.Q., Kovscek, A.R.: Sorption-induced permeability changes of coal during gas-injection processes. SPE Reserv. Eval. Eng., 792-802 (2008)

Liu, H.H., Rutqvist, J., Berryman, J.G.: On the relationship between stress and elastic strain for porous and fractured rock. Int. J. Rock Mech. Min. Sci. 46(2), 289-296 (2009)

Loret, B., Hueckel, T., Gajo, A.: Chemo-mechanical coupling in saturated porous media: elastic-plastic behaviour of homoionic expansive clays. Int. J. Solids Struct. 39, 2773-2806 (2002)

Mavor, M.J., Vaughn, J.E.: Increasing absolute permeability in the San Juan basin Fruitland formation. In: Proceedings of the Coalbed Methane Symposium, University of Alabama, Tuscaloosa, Alabama, pp. 33-45 (1997)

McKee, C.R., Bumb, A.C., Koenig, R.A.: Stress-dependent permeability and porosity of coal. In: International Coalbed Methane Symposium, University of Alabama, Tuscaloosa, Alabama, pp. 183-193 (1987)

Moyne, C., Murad, R.A.: A two-scale model for coupled electro-chemo-mechanical phenomena and Onsager's reciprocity relations in expansive clays: I homogenization analysis. Transp. Porous Med. 62, 333-380 (2006a)

Moyne, C., Murad, R.A.: A two-scale model for coupled electro-chemo-mechanical phenomena and Onsager's reciprocity relations in expansive clays: II computational validation. Transp. Porous Med. 63, 13-56 (2006b)

Pacala, S., Socolow, R.: Stabilization wedges: solving the climate problem for the next 50 years with current technologies. Science 305, 968-972 (2004)

Palmer, I., Mansoori, J.: How permeability depends on stress and pore pressure in coalbeds: a new model. Paper SPE 52607. SPE Reserv. Eval. Eng., 1(6), 539-544 (1998)

Pekot, L.J., Reeves, S.R.: Modeling the effects of matrix shrinkage and differential swelling on coal methane recovery and carbon sequestration. Paper 0328. In: International Coalbed Methane Symposium, University of Alabama, Tuscaloosa, Alabama (2003)

Robertson, E.P.: Measurement and Modeling of Sorption-Induced Strain and Permeability Changes in Coal. Idaho National Laboratory, INL/EXT-06-11832 (2005)

Robertson, E.P., Christiansen, R.L.: A Permeability Model for Coal and Other Fractured, Sorptive-Elastic Media. Idaho National Laboratory, INL/EXT-06-11830 (2006)

Rutqvist, J., Borgesson, L., Chijimatsu, M., Kobayashi, A., Jing, L., Nguyen, T.S., Noorishad, J., Tsang, C.F.: Thermohydromechanics of partially saturated geological media: governing equations and formulation of four finite element models. Int. J. Rock Mech. Min. Sci. 38, 105-127 (2001)

Rutqvist, J., Wu, Y.-S., Tsang, C.-F., Bodvarsson, G.: A modeling approach for analysis of coupled multiphase fluid flow, heat transfer, and deformation in fractured porous rock. Int. J. Rock Mech. Min. Sci. 39, 429-442 (2002)

Sawyer, W.K., Paul, G.W., Schraufnagel, R.A.: Development and application of a 3D coalbed simulator. Paper CIM/SPE 90-1119. In: International Technical Meeting Hosted Jointly by the Petroleum Society of CIM and the Society of Petroleum Engineers, Calgary, Alberta, Canada (1990)

Seidel, J.P., Jeansonne, D.J., Erickson, D.J.: Application of matchstick geometry to stress dependent permeability in coals. Paper SPE 24361. In: SPE Rocky Mountain Regional Meeting, Casper, Wyoming, pp. 433-444 (1992)

Seidle, J.P., Huitt, L.G.: Experimental measurement of coal matrix shrinkage due to gas desorption and implications for cleat permeability increases. Paper SPE 30010. In: Proceedings of SPE International Meeting on Petroleum Engineering, Beijing, China (1995)

Shi, J.Q., Durucan, S.: Changes in permeability of coalbeds during primary recovery-part 1: model formulation and analysis. Paper 0341. In: International Coalbed Methane Symposium, University of Alabama, Tuscaloosa, Alabama (2003)

Shi, J.Q., Durucan, S., Syahrial, E.: Reservoir depletion induced changes in coalbed permeability and implications for enhanced CBM recovery using $\mathrm{CO}_{2}$ injection. Geol. Belg. 7, 123-127 (2004)

Somerton, W.H., Soylemezoglu, I.M., Dudley, R.C.: Effect of stress on permeability of coal to gas and water. Int. J. Rock Mech. Min. Sci. Geomech. Abstr. 12, 129-145 (1975)

Stevens, S.H., Kuuskra, V.A., Gale, J., Beecy, D.: $\mathrm{CO}_{2}$ injection and sequestration in depleted oil and gas fields and deep coal seams: world wide potentials and costs. Environ. Geosci. 8(3), 200-209 (2001)

Wei, X.R., Wang, G.X., Massarotto, P., Golding, S.D., Rudolph, V.: A review on recent advances in the numerical simulation for coalbed-methane-recovery process. SPE Reserv. Eval. Eng., 10(6), 657-666 (2007) 
White, C.M., Smith, D.H., Jones, K.L., Goodman, A.L., Jikich, S.A., LaCount, R.B., DuBose, S.B., Ozdemir, E., Morsi, B.I., Schroeder, K.T.: Sequestration of carbon dioxide in coal with enhanced coalbed methane recovery-a review. Energy Fuels 19, 559-724 (2005)

Wilson, R.K., Aifantis, E.C.: On the theory of consolidation with double porosity. Int. J. Eng. Sci. 20, 1009-1035 (1982) 